ISSN: $1130-3743$

\title{
LOS ESTILOS EDUCATIVOS PARENTALES DESDE LOS MODELOS INTERACTIVO Y DE CONSTRUCCIÓN CONJUNTA: REVISIÓN DE LAS INVESTIGACIONES
}

\author{
The parental educational styles from the interactive and \\ the joint construction models: review of the investigations
}

Les styles éducatifs parentaux depuis les modèles interactif
et de construction conjointe: révision des recherches

Concepción AROCA MONTOLÍO* y Paz CÁNOVAS LEONHARDT**

Universidad de Valencia. Facultad de Filosofía y Ciencias de la Educación.

Departamento de Teoría de la Educación. Avda. Blasco Ibáñez, 30.

46010 Valencia.Correo-e: *concepcion.aroca@uv.es, ${ }^{* *}$ paz.canovas@uv.es

Fecha de recepción: marzo de 2012

Fecha de aceptación definitiva: julio de 2012

Biblid [(1130-3743) 24, 2-2012, 149-176]

RESUMEN

La familia como primera estructura que acoge al menor posee gran importancia en relación a otros espacios educativos en el desarrollo integral del hijo. En ella, y a través de ella, tienen lugar transmisiones decisivas y persistentes para el ser humano que vienen a realizarse por medio de estilos parentales concretos. En este artículo se plantean dos enfoques, desde nuestra perspectiva, válidos para explicar los estilos educativos en la actualidad: el modelo de construcción conjunta y el modelo interactivo, con tipologías e investigaciones que no han tenido el suficiente eco en otras publicaciones sobre el tema, y que nos parecen relevantes para abrir nuevas líneas de investigación. Los documentos científicos revisados pertenecen a investigaciones formalizadas desde la Pedagogía, Psicología y Criminología aportando, de este modo, un enfoque interdisciplinar que nos proporcionará nuevos aspectos 
vinculados a las consecuencias de los estilos educativos en el ajuste emocional y conductual de los hijos. Y será a partir de las conclusiones de las investigaciones realizadas desde el modelo interactivo que se nos planteen dudas ante lo establecido en estudios ampliamente aceptados.

Palabras clave: familia, estilos parentales, educación familiar, relaciones padreshijos, investigación familia.

\section{SUMMARY}

Family, as the first structure that receives minor, owns a big importance with regard to other educational spaces during the integral development of children. In it and through it decisive and persistent transmissions for the human being that come to realize through some parental concretes styles, take place. In this article we analyzed two approaches, from our perspective, valid for explaining the educative styles nowadays: the model of joint construction and the interactive model, with typologies and researches that have not had quite echo in other publications and those we think are outstanding to open new lines of research. Revised scientific reports are brought by Pedagogy, Psychology and Criminology generating an interdisciplinary approach that gives new perspectives linked to educative styles in the emotional and behavioral adjustment of children. And it will be starting from the conclusions of reviewed researches of the interactive model that we will establish doubts face to what was set up in widely accepted studies.

Key words: family, parenting styles, family education, parent child, relationship, family research.

\section{SOMMAIRE}

La famille comme la première structure qui reçoit l'enfant est d'une grande importance par rapport aux autres domaines de l'éducation dans le développement de l'enfant. En elle et par elle se produisent des transmissions décisives et persistantes au être humain qui se réalisent grâce à des styles parentaux spécifiques. Cet article examine deux approches, à notre avis, valables pour expliquer les styles éducatifs d'aujourd'hui: le modèle de co-construction et le modèle interactif, avec des typologies et de recherche qui n'ont pas eu assez écho dans d'autres publications, et que nous en semblent pertinentes pour ouvrir des nouvelles lignes de recherche. Les documents scientifiques que nous avons révisés sont fournis par la Pedagogie, Psychologie et Criminologie, en créant une approche interdisciplinaire qui offre des nouvelles perspectives liées aux conséquences des styles parentaux dans l'adaptation affectif et le comportement des enfants. Il sera à partir des résultats des études examinées à partir du modèle interactif que nous posons des questions aux dispositions des études largement acceptées.

Mots clés: famille, styles parentaux, éducation familier, relations père-fils, recherche famille. 


\section{INTRODUCCIÓN}

Desde hace décadas se ha considerado a la familia el primer agente educativo y socializador que interviene en el desarrollo o limitación del aprendizaje de conductas en mayor medida que otros agentes sociales (Schneider, Cavell y Hugnes, 2006). Por tanto, confirmar que la familia es el agente protagonista desde el momento de engendrar a su hijo y durante los primeros años de su proceso de socialización y educación no es baladí. Para ello, debemos recordar dos de sus mecanismos intransferibles: la transmisión genética de ambos progenitores y el ambiente donde su descendencia aprende a ser, a sentir, a pensar y a actuar en primera instancia. No obstante, cada vez existen más estudios que señalan otras influencias relevantes como son el grupo de amigos, determinados juegos, las nuevas tecnologías (Internet, redes sociales) y los medios de comunicación, entre otros, más allá de los estilos educativos.

En este artículo se analizan investigaciones de dos modelos teóricos en relación a los estilos educativos parentales: el de construcción conjunta y el interactivo. Ambos intentan superar la excesiva simplicidad que presenta el tradicional, aunque sólo el modelo interactivo defiende la búsqueda de efectos no lineales que van más allá de la suma de los efectos de dos o más variables de relevante interés explicativo.

Asimismo, se pretende determinar cuándo podemos hablar de estilo educativo y las interrelaciones que se establecen entre los aspectos que se generan en las prácticas educativas parentales, y cuándo surge un estilo educativo concreto por el que se crean unas coordenadas dentro de las que se enmarcan las estrategias y mecanismos de socialización y educación de los hijos, traducidos en actitudes, valores y comportamientos adaptativos o desadaptativos en éstos.

Del mismo modo, se establecen dos pautas que nos aportan nuevas formas de entender los estilos educativos y sus consecuencias en el ajuste social, emocional y conductual de los hijos e hijas. A partir de ellas se plantea la necesidad de abrir nuevas líneas de investigación desde la Pedagogía Familiar que profundicen en algunas conclusiones ampliamente aceptadas por la comunidad científica, que puedan estar en tela de juicio porque no bastan para dar respuesta al incremento de problemas de conducta que, en ocasiones, presentan niños y adolescentes. Realidad que también reclama la exigencia de nuevas estrategias en la práctica de profesionales que asesoran y orientan a aquellas madres y padres que muestran serios problemas para controlar el comportamiento problemático de sus hijos.

\section{Los estilos Educativos DeSDe El MODELO DE CONSTRUCCión CONJUNTA}

Un estilo educativo trata de crear unas coordenadas de regulación dentro de las que se enmarcan y describen las estrategias y mecanismos de socialización y educación que los progenitores ejercen sobre los hijos (traducidos en creencias, valores y comportamientos) que pretenden influir en su desarrollo integral. 
LOS ESTILOS EDUCATIVOS PARENTALES DESDE LOS MODELOS INTERACTIVO Y DE CONSTRUCCIÓN CONJUNTA

En esta línea, presentamos tres definiciones de estilo educativo que guardan una cierta similitud al centrarse en el aspecto práctico del término. Así, un estilo educativo tanto "representa la forma de actuar de los adultos respecto a los niños ante situaciones cotidianas, toma de decisiones o la solución de problemas" (Torío, Peña y Rodríguez, 2008, 153), como los «esquemas prácticos que reducen las múltiples y minuciosas prácticas educativas paternas a unas pocas dimensiones, que, cruzadas entre sí en diferentes combinaciones dan lugar a diversos tipos habituales de educación familiar" (Coloma, 1993, 48). Afirmación que comparten Pérez y Cánovas (1996, 141), al exponer que "son modelos o esquemas prácticos que simplifican las pautas de crianza y educación paterna en determinadas dimensiones básicas que, cruzadas entre sí en diferentes condiciones, dan lugar a diversos y habituales tipos de educación familiar".

Nuestra aportación sobre el término intenta recoger algunos de los conceptos presentes en los estudios revisados, en la medida que nos permite analizar de manera integrada esta variable en las familias y servir de marco teórico para elaborar una tipificación más específica y operativa:

Estilo educativo es el conjunto de pautas y prácticas de crianza, cuyo objetivo es la socialización y educación de los hijos, donde interactúan rasgos de personalidad, experiencias pasadas y características genéticas, tanto parentales como filiales, que se contextualizan dentro de un sistema intra, meso y macrofamiliar inmerso, a su vez, en un marco transcultural e histórico determinados (Aroca, 2010, 84).

Por otra parte, los estilos educativos se pueden explicar desde modelos teóricos, si entendemos que un modelo es un patrón basado en teorías que nos ayuda tanto a comprender la realidad de forma organizada como a aportar un significado explicativo de la realidad interpretada, con el fin de plantear acciones que transformen y mejoren dicha realidad.

De este modo, en el modelo de construcción conjunta, también llamado de influencias múltiples (Palacios, 1999), se entienden las relaciones entre progenitores e hijo/hija de proyección recíproca, cuyas estrategias de educación y socialización son tan eficaces cuanto más se adapten a la edad y a sus características personales. Además,

[...] los padres no tienen un estilo educativo fijo. El modo como se comporta un padre respecto de un niño en particular depende de la edad del niño, de su apariencia física, de su conducta habitual, de su conducta pasada, de su inteligencia y su estado de salud. Los padres confeccionan su estilo educativo a medida de cada niño [...] la educación no es algo que los padres hagan a los hijos, sino algo que los padres e hijos hacen conjuntamente» (Harris, 2002, 53).

Hecho que, al menos, indica la posible falta de consistencia de algunas investigaciones donde se ha elegido sólo a un hijo para determinar el estilo educativo parental. Incluso, desde este modelo, se indica que también influyen en dicho proceso las variables relacionadas con el escenario (intra o extrafamiliar), las personas 
que aparecen en él, la atribución de motivos, y la propia emoción desencadenada en los progenitores (Ceballos y Rodrigo, 1998).

Asimismo, y según la teoría de rasgos de Allport, existe un rasgo cardinal dominante que influye en todos los aspectos de la conducta y los atributos de una persona. Por tanto, según el rasgo cardinal que tenga el padre/madre aparecerá la prevalencia de un estilo educativo sobre otro, siendo el que se asimilará con mayor firmeza y posiblemente tendrá más influencia sobre el hijo/hija en el proceso educativo parental.

\subsection{Los estilos educativos entendidos como mixtos y cambiantes}

En la década de los 80 diferentes autores convienen que los estilos educativos son mixtos y cambiantes, no sólo teniendo en cuenta el momento de desarrollo evolutivo del hijo, la edad o el sexo de éste, sino también el orden de nacimiento y cómo interactúa con sus progenitores. De este modo, según hacia qué hijo se dirijan las pautas educativas, los progenitores pueden ejercer uno u otro estilo educativo. Cabe destacar que el momento por el que atraviesa la familia es también un factor decisivo.

Esta idea puede hacernos pensar que las investigaciones que buscan el encasillamiento de los progenitores en un estilo educativo definido a priori sólo son orientativas y no determinantes. A pesar de ello, ¿qué estilos educativos son más habituales entre los progenitores? Para dar respuesta a esta pregunta presentamos los resultados de dos estudios españoles. En primer lugar, el llevado a cabo por Torío, Peña e Inda (2008a), que tuvo como objetivo conocer qué estilos educativos eran los más utilizados por 2.965 padres/madres con hijos entre 5 y 8 años. Con esta finalidad, se fijaron tres estilos: democrático, autoritario y permisivo, precisando que cada progenitor debía tener el 50\% de las características de un estilo determinado para ser clasificado en él. En los progenitores que no alcanzaron este criterio se consideró que su estilo educativo no estaba definido. Los resultados advirtieron que sólo el 12,8\% de los encuestados (380 padres/madres) tenía un estilo definido: el democrático, frente al $87,2 \%$ que no se podía determinar e incluso presentaban pautas contradictorias. Con ello se confirma que la mayoría de los progenitores tienen estilos educativos mixtos y cambiantes.

Ante los resultados obtenidos en el estudio de Torío et al. (2008a), y según Izuzquiza (2003), esta contradicción es debida a un proceso de adaptación o respuesta que realizan los progenitores porque vivimos en una sociedad compleja y cambiante. Además, esta ambigua determinación de un estilo educativo parental es lógica si consideramos que el ser humano manifiesta diferentes conductas dependiendo de las circunstancias, lugar o persona con la que interactúa, factores que pueden dar más consistencia a los resultados obtenidos por Torío et al. (2008a).

El segundo estudio que exponemos es el de Pérez y Cánovas (1996) que según las autoras sí permitió definir estilos o tendencias dentro de los que se enmarcaba la actuación parental. Para esta investigación se utilizó una muestra de 1.200 
LOS ESTILOS EDUCATIVOS PARENTALES DESDE LOS MODELOS INTERACTIVO Y DE CONSTRUCCIÓN CONJUNTA

individuos (70\% madres y 30\% padres), encontrando cuatro tendencias: padres comprometidos en el logro, representando el $31,25 \%$ de la muestra, para los que el rendimiento académico y ocupacional es fundamental en la vida y fomentan valores como el esfuerzo y la seguridad personal. El 24,51\% de la muestra se clasificó como padres permisivos de marcado respeto a la diferencia, al fomento de la libertad, ausencia de normas y bajo nivel de exigencia a los hijos. El 23,50\% eran padres comprometidos en la educación integral de sus hijos que daban importancia a valores estéticos, culturales y éticos, al desarrollo de la creatividad, la comunicación y participación en la familia, conscientes de que son un modelo de aprendizaje para sus hijos. Y en último lugar, el 20,74\% de la muestra estaba formado por los padres invisibles que no se implicaban afectivamente con sus hijos, su comunicación era escasa/inexistente y utilizaban el castigo sin dar explicaciones.

No obstante, más allá de que se determine la existencia o no de un estilo predominante, nos planteamos una segunda cuestión: ¿cómo influye un estilo determinado en el comportamiento del hijo/hija?

\subsection{Los estilos parentales vinculados a conductas prosociales versus antisociales de los bijos e hijas}

Las tipologías de los estilos educativos parentales de las investigaciones clásicas estaban en consonancia con un modelo que tuvo su vigencia entre los años 70 y 80 que "planteaba la hipótesis de que diferentes estilos educativos repercutían de distinta forma sobre la autoestima y el autoconcepto del niño, o donde determinadas conductas de falta de supervisión o control por parte de los padres, se han asociado de forma repetida al comportamiento antisocial de los hijos" (Ato, Galián y Huéscas, 2007, 33).

En nuestra revisión sobre investigaciones de estilos educativos y comportamiento filial destacamos la de Lamborn, Mounts, Steinberg y Dornbuschu (1991), cuya muestra la formaban adolescentes entre 14 y 18 años que fueron clasificados según los estilos educativos de sus progenitores (los establecidos por Maccoby y Martin, 1983), aunque en opinión de los adolescentes. Posteriormente, estos autores contrastaron los cuatro grupos de resultados con factores como las conductas problemáticas, el desarrollo psicosocial, las destrezas interiorizadas y el logro escolar de los adolescentes, llegando a las siguientes conclusiones:

1. Los adolescentes que definían a sus progenitores con autoridad (que no autoritarios) o democráticos obtuvieron puntuaciones más elevadas en competencia social y más bajas en disfunción psicosocial y comportamental.

2. Los adolescentes que definían a sus progenitores como autoritarios obtuvieron puntuaciones medias en la obediencia y la conformidad de los adultos, pero puntuaciones bajas en autoconcepto respecto a los otros jóvenes del estudio. 
LOS ESTILOS EDUCATIVOS PARENTALES DESDE LOS MODELOS INTERACTIVO Y DE CONSTRUCCIÓN CONJUNTA

3. Los adolescentes que definían el estilo parental como permisivo-indulgente obtuvieron puntuaciones altas en autoconcepto, pero presentaban conductas desadaptativas en el ámbito escolar y abuso de sustancias tóxicas.

Desde esta óptica, el estilo que parece tener consecuencias más negativas en los hijos es el permisivo-indulgente con una escasa supervisión y control parental, y no tanto el autoritario.

Por su parte, Craig (1997), basándose también en el trabajo de Maccoby y Martin (1983), propone cuatro estilos educativos (Cuadro 1) en función del control y de la calidez que desarrollan y establecen los progenitores y las consecuencias conductuales en su descendencia siendo, de nuevo, los estilos permisivo e indiferente los que provocan conductas problemáticas y desadaptativas más graves.

\section{CUADRO 1. ESTILOS EDUCATIVOS EN FUNCIÓN DEL CONTROL Y LA CALIDEZ}

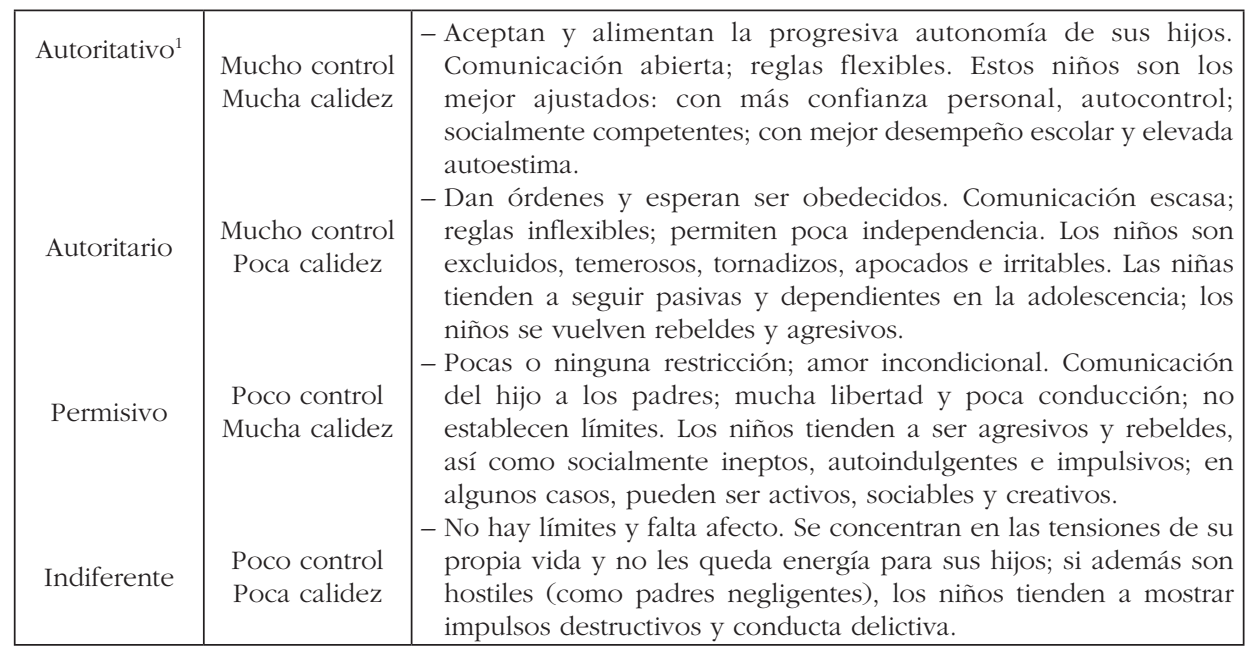

Fuente: Extraido de CRAig (1996, 316).

Por otra parte, en la investigación longitudinal de Gottman y De Claire (1997) con familias cuyos hijos e hijas tenían entre 7 y 8 años, los progenitores se clasificaron en cuatro estilos educativos: padres simplistas, desaprobadores, laissez-faire y padres verdaderos preparadores emocionales, centrando su atención prioritariamente en este último estilo.

Pero, ¿qué características tenían los progenitores preparadores emocionales del estudio de Gottman y De Claire (1997)?:

1. Es similar al estilo educativo democrático que propone Baumrind en su tipología. 
LOS ESTILOS EDUCATIVOS PARENTALES DESDE LOS MODELOS INTERACTIVO Y DE CONSTRUCCIÓN CONJUNTA

1. aprendieron a percibir las emociones de los hijos,

2. reconocían que las emociones son una oportunidad para construir una relación íntima, más profunda, y para transmitir la propia experiencia,

3. escuchaban con empatía "captando" los sentimientos que manifestaban los hijos,

4. ayudaban a los hijos a dar nombre y a verbalizar sus sentimientos,

5. ponían límites, y

6. ayudaban a sus hijos a solucionar problemas.

Transcurridos tres años, desde el inicio del estudio, Gottman y De Clair (1997) pudieron comprobar que los hijos (10 y 11 años) de padres/madres clasificados como preparadores emocionales presentaban un buen nivel en factores como rendimiento escolar, sociabilidad, bienestar emocional y salud. Incluso, en los tests que medían el coeficiente intelectual obtenían puntuaciones más altas en matemáticas y lectura. Resultados que les hicieron afirmar que: «ahora sabemos con certeza que la preparación emocional ejercida por los padres influye de modo significativo en el éxito y felicidad de los hijos/as" (Gottman y De Claire, 1997, 17).

Desde nuestra perspectiva, este tipo de padres/madres, sin lugar a dudas, ayudan al desarrollo de la inteligencia emocional en los hijos. De hecho, cada vez son más los autores que defienden el desarrollo de esta inteligencia como una de las fuentes socializadoras y educativas más prosociales. Por ejemplo, Garrido (2007) mantiene que una buena relación interpersonal se basa en la capacidad que tiene el niño para sentir las llamadas emociones morales, permitiéndole, a medida que crece, que vaya comprendiendo que los otros con los que se relaciona tienen necesidades y derechos que no pueden ser objeto de atropello en razón de sus propias necesidades o apetencias. De entre todas las emociones morales, junto con la compasión, la vergüenza y la piedad destacan por encima de éstas: la empatía y el sentimiento de culpa. Y estamos de acuerdo con Núñez Cubero et al. (2006) y Romero (2008) en que la educación emocional juega un papel primordial en la construcción de un yo positivo y resiliente.

En contraposición al estilo educativo que desarrolla la competencia social e inteligencia emocional anterior, nos interesa destacar los resultados obtenidos en el estudio de casos llevado a cabo por Nardone, Giannotti y Rocchi (2003) con hijos e hijas con graves problemas de conducta e interacciones desadaptativas y/o violentas (psicológicas y algunas físicas) contra sus progenitores. La clasificación de estilos educativos o de modelos de familia ${ }^{2}$ (Cuadro 2) fue realizada a partir del análisis de diversos casos tratados en terapia familiar.

2. Los modelos que presentamos han sido establecidos por los autores tras cinco años de trabajo conjunto de 32 investigadores y terapeutas de toda Italia afiliados al Centro de Terapia Estratégica de Arezzo. 
LOS ESTILOS EDUCATIVOS PARENTALES DESDE LOS MODELOS INTERACTIVO Y DE CONSTRUCCIÓN CONJUNTA

\author{
CUADRO 2. SíNTESIS DE LOS MODELOS EDUCATIVOS FAMILIARES \\ (NARDONE, GIANNOTTI Y ROCHI, 2003)
}

\begin{tabular}{|c|c|c|}
\hline ESTILO & COMPORTAMIENTO DE LOS PROGENITORES & COMPORTAMIENTO DE LOS HIJOS E HIJAS \\
\hline 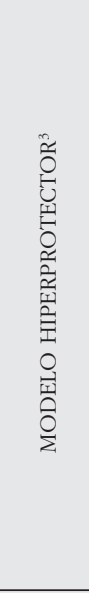 & $\begin{array}{l}\text { - Hacen todo por el hijo, solucionan sus } \\
\text { dificultades y realizan lo que debe asumir y } \\
\text { hacer él. } \\
\text { - Enfatizan el cariño, el amor, la protección y el } \\
\text { calor hacia el hijo. } \\
\text { - Se preocupan para que su retoño logre un } \\
\text { adecuado ajuste social y una salud física } \\
\text { sana. } \\
\text { - La supervisión y control se ejerce por medio } \\
\text { de preguntas (principalmente las que realiza } \\
\text { la madre). } \\
\text { - La figura paterna adopta una postura pasiva, } \\
\text { de observador y "amigo del hijo". } \\
\text { - La madre desautoriza al padre por su poca } \\
\text { o inexistente intervención. Ella asume la } \\
\text { educación y las tareas del hogar. } \\
\text { - No sancionan las conductas no adecuadas del } \\
\text { hijo. }\end{array}$ & $\begin{array}{l}\text { - No cumplen las normas porque no hay sanciones por } \\
\text { su incumplimiento. } \\
\text { - Si se rebelan contra sus progenitores, éstos ejercerán } \\
\text { más protección y control. } \\
\text { - No tienen sentido de la responsabilidad, sus } \\
\text { progenitores son los que hacen y deciden (lo aceptan } \\
\text { siempre que les convenga o favorezca). } \\
\text { - Muchos renuncian al pleno control de su vida. } \\
\text { - La supervisión y el control los eluden no dando } \\
\text { explicaciones o no contestando. } \\
\text { - No colaboran en tareas del hogar u otro tipo de } \\
\text { obligaciones familiares. } \\
\text { - No logran asumir riesgos. } \\
\text { - Presentan problemas de incertidumbre y en la } \\
\text { construcción de su autonomía porque no creen en } \\
\text { sus capacidades. } \\
\text { - Pueden presentar: depresiones, ansiedad, trastornos en } \\
\text { la alimentación, dificultad en el rendimiento académico, } \\
\text { abandono escolar y problemas de conducta. }\end{array}$ \\
\hline 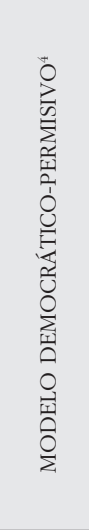 & $\begin{array}{l}\text { - Su objetivo es la armonía y la ausencia de } \\
\text { conflictos en el hogar, aunque para ello deban } \\
\text { someterse a la voluntad y deseos del hijo. } \\
\text { - Todos los miembros de la familia tienen los } \\
\text { mismos derechos. } \\
\text { - Las normas y límites que establecen no las } \\
\text { cumple el hijo; entonces, las pactan y suavizan } \\
\text { saliendo mucho mejor parado éste. } \\
\text { - Si el hijo no cumple lo establecido, no hay } \\
\text { consecuencias. } \\
\text { - Utilizan como herramienta educativa la } \\
\text { argumentación constante, que el hijo ignora y } \\
\text { ve como sermón. } \\
\text { - No "actúan" o reaccionan, son dóciles ante } \\
\text { conductas inadecuadas del hijo. } \\
\text { - La madre es la que carga con casi la totalidad } \\
\text { de las tareas educativas y del hogar. }\end{array}$ & $\begin{array}{l}\text { - Tienen todos los derechos y sus progenitores se los } \\
\text { tienen que dar o facilitar. } \\
\text { - Actitud tiránica: imponen sus necesidades y deseos } \\
\text { que deberán ser satisfechos. } \\
\text { - Presentan conductas de riesgo como: absentismo y } \\
\text { fracaso escolar, amigos antisociales, salidas nocturnas, } \\
\text { consumo de tóxicos. } \\
\text { - No cumplen las normas porque no hay castigos. } \\
\text { - Les falta de responsabilidad y autonomía. } \\
\text { - No encuentran un sostén estable, seguro y } \\
\text { tranquilizador en su padre/madre, que tanto necesitan } \\
\text { en la adolescencia. } \\
\text { - Culpan a sus propios progenitores de sus dificultades } \\
\text { para "transitar por la vida". } \\
\text { - Pueden presentar problemas como: fobias, obsesiones, } \\
\text { trastornos de la alimentación, etcétera. }\end{array}$ \\
\hline
\end{tabular}

3. Según NARDONE et al. $(2003,54)$ "aparece como la tendencia dominante de la familia italiana actual, y detrás de un adolescente tachado de "problemático" en el contexto familiar o escolar aparece muy a menudo un clima familiar hiperprotector".

4. En palabras de NARDONE et al. $(2003,70)$, "la característica que mejor distingue este modelo es la ausencia de jerarquía [...] donde los hijos son tiranos, tratados como adultos y responsables dentro del principio de igualdad ante la toma de decisiones familiares, a las que el hijo no puede responder eficazmente". 


\begin{tabular}{|c|c|c|}
\hline & $\begin{array}{l}\text { - El sacrificio es la médula espinal de las } \\
\text { relaciones parento-filiales. } \\
\text { - Si su sacrificio no es apreciado se lo reprochan } \\
\text { al hijo. } \\
\text { - Ante su sacrificio, el hijo debe responder con } \\
\text { éxitos y logros (los que ellos no consiguieron). } \\
\text { - Tienen poca vida social. } \\
\text { - Hogares con carga de ansiedad y } \\
\text { preocupaciones de las que huye el hijo. } \\
\text { - La madre es la principal responsable de la } \\
\text { educación y las tareas del hogar. } \\
\text { - El padre suele estar poco implicado en la } \\
\text { supervisión y crianza del hijo. } \\
\text { - Abdican ante la actitud impositiva del hijo } \\
\text { "porque la maternidad/paternidad es muy } \\
\text { sacrificada". }\end{array}$ & $\begin{array}{l}\text { - Piensan que se les debe dar todo lo que necesitan o } \\
\text { desean. } \\
\text { - Pueden ser violentos en sus hogares siendo sus } \\
\text { víctimas su madre/padre. } \\
\text { - Saben que cuanto más abuso ejerzan más beneficios } \\
\text { obtendrán. } \\
\text { - Presentan problemas para integrarse en el mundo } \\
\text { extrafamiliar por su nivel bajo de frustración y de } \\
\text { miedo al rechazo. } \\
\text { - Algunos optan por la reclusión en sus casas, otros en } \\
\text { estar todo el tiempo posible fuera de ella vinculándose } \\
\text { con grupos de iguales con problemas de conducta. } \\
\text { - Son dispensados de las tareas del hogar (la madre se } \\
\text { quejará pero, al mismo tiempo, le hará su tarea). } \\
\text { - Obtienen sus caprichos pero no logran satisfacción ni } \\
\text { motivación personal. } \\
\text { - Es frecuente que desarrollen actitudes de rechazo o de } \\
\text { violencia en la relación filio-parental. }\end{array}$ \\
\hline 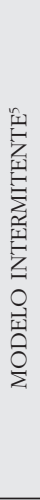 & $\begin{array}{l}\text { - Presentan actitudes de los progenitores } \\
\text { hiperprotectores, democrático-permisivos o } \\
\text { sacrificados. } \\
\text { - Establecen interacciones inconsistentes con } \\
\text { el hijo. } \\
\text { - No presentan puntos de referencia conductual } \\
\text { ni bases seguras para el hijo. } \\
\text { - Pueden solucionar el problema, pero, si los } \\
\text { resultados no son inmediatos, cambian de } \\
\text { táctica, pudiéndose perpetuar el problema. } \\
\text { - Valoran positivamente a su hijo, ellos son los } \\
\text { culpables de sus "malas" conductas. } \\
\text { - Piensan que son muy duros cuando deben } \\
\text { castigar o restringir al hijo, haciéndoles sentir } \\
\text { mal, por ello lo evitan. } \\
\text { - Abdican ante las amenazas y chantajes del hijo. }\end{array}$ & $\begin{array}{l}\text { - Al igual que los progenitores, los hijos pueden adoptar } \\
\text { comportamientos de los ya expuestos en los anteriores } \\
\text { modelos. } \\
\text { - Practican conductas déspotas e impositivas. } \\
\text { - Presentan problemas de inseguridad, falta de } \\
\text { autonomía y responsabilidad. } \\
\text { - Su actitud habitual es la de rebeldía y holgazanería. } \\
\text { - Presentan problemas de absentismo, rendimiento } \\
\text { escolar y de conducta. } \\
\text { - Exigen todo lo que consideran que son sus privilegios. } \\
\text { - Se rebelan contra las normas y límites amenazando } \\
\text { y chantajeando a sus progenitores, que ceden, para } \\
\text { salirse con la suya. } \\
\text { - Pueden presentar conductas de enfrentamiento y abusos } \\
\text { extremos (violencia física) contra su madre/padre. }\end{array}$ \\
\hline 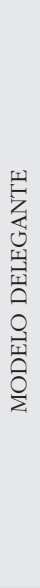 & $\begin{array}{l}\text { - Estrecha relación con sus familias de origen. } \\
\text { - Dejan a su hijo al cuidado de sus progenitores } \\
\text { (abuelos del niño). } \\
\text { - No han establecido una real emancipación } \\
\text { de su familia, ni adquirido responsabilidad } \\
\text { parental. } \\
\text { - Pueden adoptar modelos educativos idénticos } \\
\text { al de sus familias de origen. } \\
\text { - Suelen delegar o renunciar, parcial o } \\
\text { totalmente, a sus roles enmarcados dentro de } \\
\text { su propio estilo educativo. } \\
\text { - En la adolescencia del hijo se inicia una } \\
\text { rivalidad entre los adultos implicados en la } \\
\text { crianza de éste; gana quien se "gane el amor" } \\
\text { del adolescente, aunque sea cediendo a todas } \\
\text { las peticiones de éste. }\end{array}$ & $\begin{array}{l}\text { - Siguen las normas de las dos familias que les son más } \\
\text { cómodas y ventajosas. } \\
\text { - Ante las circunstancias educativas que viven, optan } \\
\text { por desacreditar y/o desautorizar al adulto que les } \\
\text { marque más disciplina. } \\
\text { - No ven como figura de autoridad a los progenitores } \\
\text { ni a los abuelos. } \\
\text { - A los abuelos los ven como negociadores para } \\
\text { conseguir lo que quieren de sus progenitores, y como } \\
\text { mediadores ante situaciones conflictivas con ellos. } \\
\text { - Utilizan la desautorización de los adultos en su propio } \\
\text { beneficio. } \\
\text { - Presentan problemas de rendimiento académico, } \\
\text { conductas de riesgo, pequeños hurtos, etcétera. } \\
\text { - Presentan una clara evitación social que se torna } \\
\text { estrategia ante situaciones nuevas o difíciles. } \\
\text { - Cuando sus progenitores intentan marcar límites } \\
\text { son poco creíbles para ellos, incluso los consideran } \\
\text { transitorios. }\end{array}$ \\
\hline
\end{tabular}




\begin{tabular}{|c|c|c|}
\hline 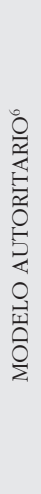 & $\begin{array}{l}\text { - Persiguen tener el poder mediante una } \\
\text { jerarquía rígida. } \\
\text { - Se presentan como el modelo a imitar. } \\
\text { - Dictan las normas disciplinarias que son el } \\
\text { fundamento de la convivencia. } \\
\text { - Satisfacer los deseos del hijo comporta el } \\
\text { cumplimiento previo de sus obligaciones, y el } \\
\text { logro de las metas que ellos establecen. } \\
\text { - El incumplimiento de lo establecido supone el } \\
\text { castigo, a veces contundente. } \\
\text { - Si el padre es el autoritario se muestra distante, } \\
\text { no comunicativo o presenta una comunicación } \\
\text { tensa y poco fluida que genera tensión en la } \\
\text { casa. } \\
\text { - La madre suele ser la mediadora y conciliadora } \\
\text { entre el padre y el hijo. }\end{array}$ & $\begin{array}{l}\text { - Aceptan las pautas impuestas de pequeños, en la } \\
\text { adolescencia pueden llegar a enfrentarse con violencia } \\
\text { a los progenitores. } \\
\text { - Saben que deben contentar a sus progenitores } \\
\text { obteniendo titulaciones académicas y competencias } \\
\text { para lograr el éxito. } \\
\text { - Pueden adoptar posturas de alejamiento y frialdad } \\
\text { hacia sus progenitores. } \\
\text { - Otros pueden optar por la tenacidad, responsabilidad } \\
\text { y consiguen antes que otros la autonomía. } \\
\text { - Suelen abandonar pronto la familia. } \\
\text { - En ocasiones culpan a la madre por dejarse amedrentar } \\
\text { por el padre y/o por no defenderle ante su trato. } \\
\text { Pueden llegar a maltratarla. } \\
\text { - Pueden adoptar posiciones radicalmente opuestas al } \\
\text { padre (no siempre exentas de violencia). }\end{array}$ \\
\hline
\end{tabular}

Fuente: Aroca (2011, 103-106).

Nos parece interesante advertir que Nardone et al. (2003) incluyen a los hijos que "sufren" dentro del modelo autoritario en dos extremos comportamentales: adolescentes con problemas de conducta o adolescentes adaptados, responsables y con determinación. Es el único de los modelos explicados por los autores que no perjudica a casi la mitad de los hijos/hijas. Dicho esto, no olvidemos que este estilo sigue siendo uno de las tendencias menos aceptadas por parte de los expertos. Quizá deberíamos analizar las características de varios hijos de una misma familia que son educados con el estilo autoritario para determinar si las consecuencias siempre son negativas o dependen de las características del hijo el que sea o no adecuado para su ajuste.

De otro lado, también consideramos oportuno hacer referencia a otra investigación que relaciona el estilo educativo con las conductas antisociales o delictivas de los hijos adolescentes. Nos referimos al de Henggeler (1989), que analiza y compara dos factores vinculados a la transmisión familiar: el afecto de los progenitores y el estilo de control parental ejercido en 112 familias de jóvenes delincuentes y 51 familias con hijos no delincuentes que vivían en el mismo barrio, obteniendo las siguientes conclusiones:

5. Es uno de los modelos que mejor explica el ciclo de la violencia filio-parental. Por ejemplo, a veces las tácticas disciplinarias de los progenitores son el razonamiento, sermones o argumentos pero cuando el hijo no se comporta como esperan, pasan a las restricciones y a los castigos. Pero si el hijo se rebela de forma contundente y agresiva, se rinden, quitando las restricciones. Esta "retirada" refuerza el poder del hijo/hija sobre ellos.

6. NARDONE et al. (2003) presentan a los hijos que "Sufren" enmarcados en dos extremos: adolescentes con problemas o adolescentes ajustados, responsables y con determinación. Es el único de los modelos que da dos caras de la misma moneda, pudiendo no ser tan negativo en casi la mitad de los hijos. 
LOS ESTILOS EDUCATIVOS PARENTALES DESDE LOS MODELOS INTERACTIVO Y DE CONSTRUCCIÓN CONJUNTA

1. El afecto parental se refiere a la cantidad y calidad de dedicación de los progenitores para con sus hijos (cuánto tiempo haciendo qué). Este factor encuentra su fundamento teórico en trabajos que apoyan la idea de que la falta de atención, la poca ayuda a la madre y el bajo sentimiento de pertenencia familiar se vinculan con conductas antisociales o delictivas en los hijos (Carter, 1982; Henggeler, 1989).

2. El estilo de control parental ejercido se refiere a las estrategias que utilizan los progenitores para fijar normas y límites con los que constituir tanto las demandas como el control del comportamiento del hijo. Este factor se basa a nivel teórico en diversos estudios (Farrington y Welsh, 2007; Synder y Patterson, 1997b, 1995; West y Farrington, 1973) cuyas conclusiones se dirigían a afirmar que los progenitores de jóvenes antisociales y delincuentes habitualmente:

- utilizaban estrategias de disciplina que no conseguían controlar las conductas de sus hijos por su ineficacia, a causa de una supervisión inadecuada (no estar suficientemente pendientes de los hijos);

- no corregían conductas indeseadas ni enseñaban o indicaban a los hijos conductas alternativas o apropiadas, y

- utilizaban estrategias coercitivas.

Tras los resultados obtenidos en su estudio, Henggeler (1989) estableció interacciones entre las estrategias de control parental ejercidas y el afecto familiar, para demostrar que pueden dar lugar a determinados comportamientos en el hijo, tal y como podemos observar en el siguiente cuadro.

CUADRO 3. INTERACCIONES ENTRE ESTRATEGIAS DE CONTROL Y EL AFECTO PARENTAL

DIMENSIÓN AFECTIVA: aceptación, responsividad, dedicación al hijo

\begin{tabular}{|c|c|c|c|}
\hline 。ิ & & Alta & Baja \\
\hline 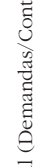 & Alta & $\begin{array}{l}\quad \text { Padres implicados con autoridad: } \\
\text { - Alta independencia/responsabilidad } \\
\text { - Baja agresión } \\
\text { - Alta autoestima }\end{array}$ & $\begin{array}{l}\text { Padres autoritarios: } \\
\text { - Déficit de internalización moral } \\
\text { - Baja competencia social } \\
\text { - Baja autoestima }\end{array}$ \\
\hline 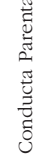 & Baja & $\begin{array}{l}\quad \text { Padres indulgentes, permisivos: } \\
\text { - Alta impulsividad } \\
\text { - Alta agresividad } \\
\text { - Baja independencia/responsabilidad }\end{array}$ & $\begin{array}{l}\text { Padres indiferentes/no implicados: } \\
\text { - Serios déficits en el desarrollo } \\
\text { cognitivo y social }\end{array}$ \\
\hline
\end{tabular}

Fuente: Garrido, Stangeland y Redondo (2006, 315), adaptado de HengGeler (1989, 36-37).

Por tanto, a partir de las diferentes interacciones establecidas (Cuadro 3) podemos llegar a las siguientes conclusiones: 
1. Para que se dé un desarrollo infantil óptimo o prosocial, debe existir un buen nivel afectivo combinado con un alto nivel de demandas y control parental. Es decir, progenitores implicados en la educación y en el día a día de su hijo, con autoridad. Para Henggeler (1989), el resultado sería un hijo independiente. Estos resultados también los hallamos en Lamborn et al. (1991).

2. Poca afectividad junto con demandas y control parental altos generan progenitores autoritarios que no educan eficazmente a su hijo. Como resultado aparece un adolescente con baja competencia social, deficiencias en la internalización de las normas, baja autoestima y no toma decisiones, sino que cumple las que sus progenitores establecen, ya que de no hacerlo la respuesta parental es contundente.

3. Cuando el control parental ante las actividades que realiza el hijo es intermitente o inexistente junto con alta afectividad, comporta un estilo educativo permisivo-protector. En este caso, tenemos a un hijo con alta agresividad e impulsividad, baja independencia y baja responsabilidad.

4. Bajos niveles de afecto y control parental supondrían un estilo educativo indiferente y con poca implicación en la educación del hijo. Lo más habitual es encontrar a un adolescente cuyo desarrollo cognitivo es deficitario y con problemas en sus relaciones interpersonales. En este apartado habría mayor número de jóvenes antisociales o con graves problemas conductuales con su padre y madre.

Asimismo, existen otras investigaciones clásicas en Criminología (Synder y Patterson, 1987; West y Farrington, 1973; Hirschi, 1969; Glueck y Glueck, 1956) que correlacionan hábitos de crianza y conducta agresiva o delictiva en el hijo. Por ejemplo, adolescentes antisociales y/o delincuentes reproducen las conductas violentas tanto en la calle como en sus hogares, y "los padres de estos chicos suelen intentar controlar sus conductas antisociales mediante el uso frecuente de castigo. Cuando un chico se comporta violentamente, los padres suelen actuar también violentamente, pese a que comprueban reiteradamente que suele resultar poco efectivo. Muchos jóvenes aceleran su propia violencia a partir de la imitación de la violencia de los padres" (Garrido, Stangeland y Redondo, 2006, 314-315). Lo que nos lleva a concluir que determinados padres y madres establecen un ciclo de violencia parento-filial que puede tener como consecuencia el aprendizaje de nuevas conductas violentas y de relación por parte del hijo/hija, así como un estilo coercitivo parental (Patterson, 1986).

Por otra parte, para comprender mejor la influencia del estilo educativo en el comportamiento del hijo/hija no necesitamos compartir el mito de la tabla rasa (Pinker, 2004) o el modelo de aprendizaje social en el contexto familiar como la explicación única del aprendizaje de conductas desadaptativas porque también la genética importa. De este modo, aparece el binomio ambiente-herencia que va a condicionar la relación filio-parental, y viceversa, el aprendizaje de conductas antisociales o el potenciar la predisposición genética de la agresividad. Incluso, 
LOS ESTILOS EDUCATIVOS PARENTALES DESDE LOS MODELOS INTERACTIVO Y DE CONSTRUCCIÓN CONJUNTA

hay autores que dan un paso más allá y también hablan de incapacidad parental para educar de forma óptima a los hijos con tendencias antisociales. Por citar un ejemplo, Garrido $(2005,358)$ afirma "que los niños con una personalidad proclive a la delincuencia tienden a heredar parte de esa tendencia de sus padres, por tanto la conclusión es que las familias de donde proceden esos niños están poco cualificadas para darles ese tipo de atención de calidad".

De igual forma, los diferentes estudios revisados en este apartado coinciden en la importancia del control parental. Sin embargo, surge la controversia cuando los expertos intentan acordar la mayor o menor importancia del control para el ajuste y desarrollo óptimo del hijo/hija. Incluso, aunque autores como Jacobson y Crockett (2000) apoyan la importancia del control, los investigadores difieren a la hora de decidir qué conductas o dimensiones se vinculan con éste (supervisión, conocer lo que hace, dónde va y con quién va el hijo, fijar límites, exigir responsabilidad, entre otras). Del mismo modo, encontramos autores que incluso establecen dos tipos de control: el psicológico y el conductual, y sus efectos perniciosos u óptimos en el ajuste del hijo. Todo ello implica diversidad de criterios y resultados poco consistentes acerca de las ventajas y los tipos del control parental más adecuados (Parra y Oliva, 2006; Barber y Harmon, 2002).

No obstante, y ante la expectativa de que surjan nuevos datos que revelen lo opuesto, diferentes autores coinciden en que, por una parte, el control que ejercen los padres es conveniente para la prevención de conductas problemáticas en los hijos y, por otra, contemplan la ventaja del control para el desarrollo y ajuste del adolescente (Fletcher, Steinberg y Williams-Weeler, 2004; Pettit y Laird, 2002; Jacobson y Crockett, 2000). Como afirman Oliva, Parra, Sánchez-Queija y López (2007, 50), "cuando el control o supervisión es ejercido en un contexto caracterizado por el afecto y la comunicación, es más probable que alcance sus objetivos socializadores de prevención de problemas conductuales".

Con todo, además de ser progenitores exigentes y que ejercen un adecuado control, también se debe establecer una comunicación interpersonal eficaz (empática y asertiva), y expresar afecto hacia el hijo para, de este modo, establecer unas adecuadas relaciones intrafamiliares. Al respecto, el control parental según Oliva et al. (2007, 55) "Sólo resultó eficaz cuando iba acompañado de afecto y comunicación, y en su ausencia, además de no prevenir los problemas de conducta, estaba asociado al desajuste emocional". En esta dirección, Stattin y Kerr (2000) entienden el control parental como facilidad para obtener información del hijo más allá del hogar, pero además guarda una relación positiva con el ajuste comportamental de los hijos si son éstos quienes comunican sobre lo que ellos hacen o con quién van, resaltando que para que den dicha información es necesario un contexto familiar afectivo y comunicativo. 
LOS ESTILOS EDUCATIVOS PARENTALES DESDE LOS MODELOS INTERACTIVO Y DE CONSTRUCCIÓN CONJUNTA

\author{
CUADRO 4. INVESTIGACIONES SOBRE ESTILOS EDUCATIVOS \\ EN EL S. XXI DESDE EL MODELO DE CONSTRUCCIÓN CONJUNTA
}

\begin{tabular}{|c|c|}
\hline AUTORES & INVESTIGACIONES \\
\hline $\begin{array}{l}\text { - Estévez et al., 2007; Cava et al., 2006; Molpereces et } \\
\text { al., 2001; López et al., 2001; Aunola et al., } 2000\end{array}$ & $\begin{array}{l}\text { Analizan componentes del estilo educativo que facilitaban la } \\
\text { conformación de un sistema de valores en los hijos, y el desarrollo de } \\
\text { valores que les proporcionaban las competencias psicosociales más } \\
\text { vinculadas al proyecto de vida futura, en términos de satisfactorio y } \\
\text { provechoso. }\end{array}$ \\
\hline $\begin{array}{l}\text { - Oliva et al., 2007; García et al., 2002; Herrera et al., } \\
\text { 2001; Kaufmann et al., 2000; Aunola et al., } 2000\end{array}$ & $\begin{array}{l}\text { Establecen una asociación positiva entre prácticas educativas del } \\
\text { estilo democrático y el ajuste socioemocional o competencia social } \\
\text { en hijos adolescentes. }\end{array}$ \\
\hline $\begin{array}{l}\text { - Estévez et al., 2007; Cava et al., 2006; Pérez de } \\
\text { Pablos, 2003; García et al., } 2002\end{array}$ & $\begin{array}{l}\text { Asocian estilos educativos y competencia social que irán desarrollando } \\
\text { los hijos durante la adolescencia, en su relación con los compañeros } \\
\text { del contexto escolar, o en la aceptación del hijo por parte de sus } \\
\text { iguales, a lo largo de la escolarización. }\end{array}$ \\
\hline $\begin{array}{l}\text { - Oliva et al., 2007; Laible y Carlo, 2004; Fletcher et } \\
\text { al., } 2004\end{array}$ & $\begin{array}{l}\text { Comparan el estilo educativo ejercido por cada uno de los } \\
\text { progenitores por separado para determinar cuál es el que más } \\
\text { influye en el desarrollo del hijo, y la percepción que éste tiene de } \\
\text { los estilos ejercidos por su madre y padre. }\end{array}$ \\
\hline $\begin{array}{l}\text { - Parra y Oliva, 2006; Fletcher et al., 2004; Silk et al., } \\
\text { 2003; Galambos et al., 2003; Pettit y Laird, 2002; } \\
\text { Barber y Harmon, 2002 }\end{array}$ & $\begin{array}{l}\text { Descubren una asociación tanto positiva como negativa entre el } \\
\text { control psicoemocional y conductual ejercido por los progenitores y } \\
\text { el ajuste interno y externo de los hijos. }\end{array}$ \\
\hline - Orte y Gifes, 2006 y 2005; Corvo y Williams, 2000 & $\begin{array}{l}\text { Asocian algunos elementos que aparecen en los estilos educativos y } \\
\text { la calidad de relación parento-filial, con los estilos de vida del hijo } \\
\text { adolescente en situación de riesgo }\end{array}$ \\
\hline $\begin{array}{l}\text { - Alonso y Román, 2005; Kim y Chung, 2003; García } \\
\text { et al., 2002; Warash y Markstrom, } 2001\end{array}$ & $\begin{array}{l}\text { Buscan las correlaciones entre el estilo educativo y algunas de sus } \\
\text { dimensiones (como el afecto) vinculadas a la autoestima del hijo. }\end{array}$ \\
\hline $\begin{array}{l}\text { - Lengua y Kovacs, 2005; Sanson et al., 2004; Hyde et } \\
\text { al., 2004; Gallagher, } 2002\end{array}$ & $\begin{array}{l}\text { Correlacionan el temperamento difícil del hijo y los estilos educativos } \\
\text { que provoca en sus progenitores, para conocer los factores que } \\
\text { pronostican una crianza óptima o problemática de los progenitores } \\
\text { con este tipo de hijos. }\end{array}$ \\
\hline $\begin{array}{l}\text { - Parke et al., 2004; Pérez de Pablos, 2003; Peralbo } \\
\text { y Fernández, 2003; Kim y Chung, 2003; Balzano, } \\
\text { 2002; Kim y Rohner, 2002; Chao, 2001; Pérez Díaz } \\
\text { et al., } 2001\end{array}$ & $\begin{array}{l}\text { Estudian tanto los estilos educativos como el comportamiento de los } \\
\text { progenitores inmigrantes en contextos interculturales. Destacamos } \\
\text { las conclusiones halladas al correlacionar algunas dimensiones de } \\
\text { estilos educativos y los logros/éxitos académicos de los hijos. }\end{array}$ \\
\hline $\begin{array}{l}\text { - Musitu y García, 2004, 2001; Wang y Li, 2003; Chao, } \\
2001\end{array}$ & $\begin{array}{l}\text { Cuestionan la idea de que los efectos de los tipos de socialización } \\
\text { y estilos educativos parentales sean directamente generalizables } \\
\text { entre diferentes culturas (en este caso, la española y la china con } \\
\text { la anglosajona), al menos, en el autoconcepto académico y en la } \\
\text { competencia/ ajuste social del hijo/hija. }\end{array}$ \\
\hline $\begin{array}{l}\text { - Stanger et al., 2004; Parke et al., 2004; Thompson et } \\
\text { al., 2002; Corvo y Williams, } 2000\end{array}$ & $\begin{array}{l}\text { Relacionan determinados estilos educativos de familias en situación de } \\
\text { riesgo, factores antisociales de los progenitores } \text {, }^{8} \text { y sus consecuencias } \\
\text { en las conductas antisociales de los hijos adolescentes. }\end{array}$ \\
\hline
\end{tabular}

Fuente: AROCA (2011, 113-115).

7. Consumo de alcohol y drogas, trastornos/hábitos alimenticios, uso de armas y problemas escolares, entre otros.

8. Alcoholemia, consumo de sustancias tóxicas, actos delictivos y malos tratos familiares. 
LOS ESTILOS EDUCATIVOS PARENTALES DESDE LOS MODELOS INTERACTIVO Y DE CONSTRUCCIÓN CONJUNTA

Así, el término comunicación intrafamiliar toma relevancia tanto en el estilo educativo como en el comportamiento del hijo. De hecho, "en la actualidad, se han de tener en cuenta cuatro aspectos distintos en las conductas de los progenitores: afecto en la relación, el grado de control, el grado de madurez y la comunicación entre padres-hijos (Moreno y Cubero, 1990; Solé, 1998; Ochaita, 1995)" (citado en Torío et al., 2008b, 154) que influirán, ciertamente, en el desarrollo de estos últimos. En efecto, en diversas investigaciones se ha demostrado que los hijos que perciben más afecto parental y una fluida y óptima comunicación intrafamiliar muestran un adecuado desarrollo prososocial, así como un mayor ajuste y bienestar emocional (Collins y Lauren, 2004; Parra, Oliva y SánchezQueija, 2004).

Del mismo modo, desde la última década del siglo pasado, las investigaciones están encaminadas en vislumbrar otras posibles relaciones entre diferentes estilos educativos y diversas variables como estilos de vida en adolescentes en riesgo, configuración del sistema de valores, comportamiento asocial, autoestima, relaciones interpersonales con el grupo de iguales, etcétera, que analizan tanto nuevas relaciones no lineales de los estilos educativos y las consecuencias en la conducta del hijo, como otras influencias que también educan y socializan fuera del contexto familiar.

En otro orden de cosas, y con el fin de conocer las líneas de investigación llevadas a cabo en la primera década del siglo xxi dentro del modelo de construcción conjunta, hemos realizado una revisión sucinta de algunas investigaciones (Cuadro 4). Todas ellas tienen un denominador común que es la vinculación entre estilos educativos parentales (estudiados entre las décadas de los años 70 y 80) y el desarrollo social, académico, conductual y emocional (incluido el moral) de sus hijos.

Tras esta revisión, pensamos que la variedad existente en los resultados obtenidos, las diferentes muestras y metodologías utilizadas hacen complejo cualquier intento de aunar criterios o conclusiones generalizables. Sin embargo, también es cierto que esta profusión de estudios nos aporta un amplio bagaje de conocimientos y miradas acerca de los estilos educativos, sus consecuencias vinculadas a dimensiones específicas (algunas novedosas) y todo ello nos abre a nuevas vías de investigación. Precisamente, debido a estos datos, encontramos diferentes definiciones de estilos educativos desde donde parten las investigaciones, se pone el acento en unas variables sobre otras disponiendo así su tipología y, finalmente, se utilizan metodologías vinculadas sólo al modelo de construcción conjunta, quedando al margen otro modelo de igual relevancia científica como es el interactivo.

\section{EL MODELO INTERACTIVO}

Los estudios llevados a cabo desde los modelos tradicionales (Becker, 1964; Schaefer, 1959; Sears, Maccoby y Levin, 1957; Baldwin, Kalhorn y Breese, 1945) y los de construcción conjunta (Gottman y De Claire, 1997; Craig; 1997; Maccoby y Martin, 
LOS ESTILOS EDUCATIVOS PARENTALES DESDE LOS MODELOS INTERACTIVO Y DE CONSTRUCCIÓN CONJUNTA

1983; Baumrind, 1971a, 1971b; Hoffman, 1970) admiten que los estilos educativos parentales producen unas consecuencias específicas en el desarrollo socioemocional y conductual del hijo. Sin embargo, la mayoría de las tipologías expuestas en el apartado anterior se basan en estudios de tipo correlacional, o simplemente contemplan algunas variables de los modelos sistémicos de la familia que examinan las relaciones paterno-filiales donde el hijo adopta un rol relativamente pasivo. En contraposición, el modelo interactivo propone y suscita la búsqueda de efectos del estilo educativo que supere la idea sumatoria de la correlación existente entre diversas variables o interacciones, dando un paso más allá de lo propuesto en el modelo de construcción conjunta acerca de que los estilos educativos son mixtos y cambiantes en función de diversas variables y las consecuencias de éstos en el ajuste de los hijos.

En definitiva, el modelo interactivo defiende que la construcción conjunta parento-filial del estilo educativo no siempre logra con eficacia educar y socializar al hijo/hija, porque no es una mera suma de efectos lo que hace posible dicho logro. Proyecta un avance indicando que en función de algunas características del hijo/hija hará que estilos denostados, como el autoritario/restrictivo o el de bajo control/laxo, sean eficaces en el proceso educativo de según qué hijos/hijas para que se produzca un adecuado ajuste socioemocional y conductual. Y, del mismo modo, en función del rasgo cardinal del hijo/hija un estilo educativo concreto puede ser más o menos eficaz en su educación. De hecho, Lykken (2000) señala que existen niños que por sus características de personalidad (abarcando el temperamento ${ }^{9}$ y las habilidades $\operatorname{cognitivas}^{10}$ ) serán mucho más difíciles de socializar y educar que otros, y que requieren de progenitores muy competentes para poder neutralizar sus tendencias antisociales, más allá de un estilo educativo concreto.

\subsection{Interacciones entre el estilo educativo, temperamento y desarrollo socio-emocional}

En el modelo interactivo se sitúan investigaciones que analizan las interacciones existentes entre el estilo educativo y el temperamento del hijo, por una parte, y el desarrollo o ajuste socioemocional, por otra. Algunos trabajos revisados nos aportan nueva información al concluir que un mismo estilo educativo puede tener consecuencias antagónicas en un hijo/hija dependiendo de variables como su temperamento, su nivel de miedo o su capacidad de empatía.

9. Según Buss (1995) las características fundamentales del temperamento son la emocionalidad (capacidad de reacción afectiva), la actividad (entendida como nivel arousal), la sociabilidad (preferencia por la compañía) y la impulsividad (tendencia a responder sin reflexión). Como es evidente, la violencia en el ser humano está vinculada a estos procesos de emocionalidad, de ahí la relevancia del temperamento.

10. Como: la metacognición que implica valorar críticamente el propio pensamiento, la resolución de problemas, el pensamiento lateral que supone pensar en diferentes alternativas para la solución de problemas, la reflexión o analizar las consecuencias de la conducta. 
LOS ESTILOS EDUCATIVOS PARENTALES DESDE LOS MODELOS INTERACTIVO Y DE CONSTRUCCIÓN CONJUNTA

De este modo, Kochanska (1993, 1995 y 1997a, 1997b) quería demostrar la interacción y su dirección entre los estilos educativos y el temperamento ${ }^{11}$ y su influencia en el comportamiento ajustado como la conciencia ${ }^{12}$, en niños de dos años hasta final de preescolar, correlacionado cuando la madre ejercía una disciplina suave, concluyendo que: (a) resultaba ineficaz en los niños no miedosos ${ }^{13}$ al no estimular los niveles mínimos de miedo requeridos para interiorizar las normas; (b) en contrapartida, era eficaz en los niños miedosos porque impulsa el desarrollo de autocontrol manteniendo bajos los niveles de ansiedad.

El estudio de Blackson, Tarter y Mezzich (1996) tenía como objetivo encontrar la posible correlación entre disciplina parental y temperamento filial en relación a conductas externalizantes ${ }^{14}$ e internalizantes en hijos preadolescentes, cuando existía un estilo educativo con disciplina negativa (alto control y baja afectividad) hallando que en hijos con un temperamento "dificil" " era más probable que provoquen una disciplina severa y negativa en sus progenitores que, y a la vez, sostenía un mal ajuste socioemocional que los hijos no difíciles.

La investigación de Crockenberg (1981) pretendía demostrar la interacción existente entre la irritabilidad del recién nacido, el apoyo social de la madre y la seguridad del apego al año de vida, cuando el estilo de crianza comportaba flexibilidad educativa. Los resultados que obtuvo fueron: (a) los niños con predisposición al malestar necesitaban un estilo educativo flexible y un mayor número de recursos para construir relaciones de apego seguro con las madres, y (b) los niños que de recién nacidos eran irritables, presentaron apego inseguro si las madres tenían poco apoyo social.

Ampliando conclusiones al respecto, existen dos investigaciones, la de Rutter (1997) y la de Mangelsdorf, Gunnar, Kestenbaum, Lang y Andreas (1990), cuyo objetivo era demostrar la interacción y dirección entre la relación de apego materno

11. Para GARRIDO (2007) el temperamento es la base biológica de la personalidad, y constituye una impronta que facilita o dificulta, por ejemplo, el desarrollo de la empatía y la capacidad de sentir miedo, que, dicho sea de paso, son dos mecanismos de aprendizaje necesarios para educarse en valores, cumplir normas, sentir remordimientos, temer el castigo, etcétera, que, indiscutiblemente, facilitará el ajuste socioemocional posterior.

12. Kochanska define la conciencia como la internalización de las normas, integrando en este concepto factores afectivos, motivacionales y cognitivos.

13. La falta de miedo, de la que habla Kochanska, dificulta el sentirse avergonzado, culpable y empático; para llegar a esta conclusión llevó a cabo diversos trabajos longitudinales donde concluyó que los niños más miedosos tenían más remordimientos tras portarse mal y les importaban las consecuencias de esa conducta, lo que, a su vez, les facilita seguir las normas y límites establecidos por sus progenitores.

14. Se refieren a conductas agresivas, desadaptativas o disruptivas.

15. Los niños con un temperamento difícil son aquellos que hacen que sus padres/madres se enfaden, se crean incapaces o se sientan culpables por no lograr sus objetivos educativos; pueden crear tensión en el hogar generando alteraciones familiares (estrés o discusiones entre los progenitores), provocar problemas con los hermanos y desencadenar problemas emocionales propios. 
LOS ESTILOS EDUCATIVOS PARENTALES DESDE LOS MODELOS INTERACTIVO Y DE CONSTRUCCIÓN CONJUNTA

con el hijo y el posterior ajuste socioemocional de éste. Las variables correlacionadas eran el estilo educativo, temperamento y seguridad de apego cuando existía una represión materna. Los hallazgos encontrados concluyeron que: (a) tanto una alta como baja represión materna no correlaciona con el apego en niños que no presentan tendencia al malestar, (b) una baja represión promueve un apego seguro en niños con tendencia al malestar y (c) sólo un estilo educativo maternal flexible y abierto puede fomentar una adecuada relación de apego en niños altamente irritables.

Por su parte, la investigación de Park, Belsky, Putnam y Crnic (1997) se marcó como objetivo señalar la posible interacción entre temperamento y ajuste socioemocional relacionados con problemas de tipo internalizante ${ }^{16}$ en los hijos, cuando existía estilo educativo restrictivo. Las conclusiones a las que llegaron eran que dicho estilo beneficia a los niños con alta emocionalidad negativa ${ }^{17}$ favoreciendo un buen ajuste socioemocional posterior. Al respecto, Synder y Patterson (1997a, 1995) establecen el tipo de pautas educativas (disciplina y autoridad) que deben instaurar las madres para lograr el ajuste socioemocional con mayor facilidad a sus hijos con un temperamento difícil ya desde los 5 años.

El estudio de Colder, Lockman y Wells (1997) pretendió demostrar interacciones entre estilo educativo y conducta del hijo/hija a partir de su temperamento. Sus conclusiones fueron: (a) el estilo educativo con disciplina severa pronostica los niveles de agresividad en hijos con valores medios o altos de miedo, pero no con los que tienen un valor bajo; (b) poco control parental se vincula con mayores niveles de agresividad en hijos con alto nivel de actividad, pero no con los que presentan niveles bajos o medios; (c) una baja implicación parental (poco control y supervisión) es perjudicial en niños que presentan altos niveles de actividad; (d) una implicación parental alta (disciplina severa) es más negativa en niños con alto nivel de miedo; (e) la disciplina severa vaticina depresión únicamente en niños con niveles altos de miedo, y (f) los niños con altos niveles de actividad requieren estilos educativos parentales más restrictivos; en contrapartida, los niños miedosos necesitan menos control y estilos educativos menos severos para un buen ajuste socioemocional.

El trabajo de Bates, Pettit, Dodge y Ridge (1998) tuvo como propósito exponer la interacción entre el estilo educativo materno con alto/bajo control restrictivo, y el temperamento del niño en relación con problemas externalizantes, hallando que: (a) un alto control restrictivo augura un bajo nivel de comportamiento externalizante en niños que presentan una alta resistencia al control, es decir, que ignoran los intentos parentales por detener o redirigir su conducta, y (b) un bajo control restrictivo pronostica mayor nivel de conducta externalizante sólo en niños que

16. Como la depresión, el estrés o la ansiedad.

17. Son niños/niñas que tienen un bajo nivel de contención, de empatía y de sentimiento de culpa. Ocurre lo contrario en niños con una emocionalidad positiva. 
LOS ESTILOS EDUCATIVOS PARENTALES DESDE LOS MODELOS INTERACTIVO Y DE CONSTRUCCIÓN CONJUNTA

presentan una alta resistencia al control. De este modo, un mayor control favorece que los niños resistentes desarrollen controles internos que les facilitarán un ajuste socioemocional posterior.

El estudio de Early, Rimm-Kaufman, Cox y Saluja (1999) puso el acento en la interacción entre estilo educativo positivo (poca restricción y alta afectividad), temperamento y ajuste socioemocional relacionados con problemas de tipo internalizante, concluyendo que dicho estilo prevé una menor inhibición socioemocional en niños con emocionalidad negativa.

Por su parte, Stanhope (1999) pretendió evidenciar la interacción entre el temperamento y la disciplina parental en relación con la conducta prosocial y sus efectos cuando el estilo educativo tenía un bajo control parental. Sus conclusiones fueron que: (a) sólo en niños con alta emocionalidad negativa este estilo educativo se relaciona con una mayor frecuencia de la conducta prosocial de "compartir", y (b) en niños miedosos promueve el desarrollo de conductas prosociales con sus iguales al mantener bajos niveles de ansiedad. De este modo, Stanhope concluyó lo mismo que Kochanska.

La investigación realizada por Lengua, Wolchik, Sandler y West (2000) tuvo como fin manifestar la relación e influencias existentes entre el ajuste social del hijo y el divorcio de los progenitores cuando el estilo educativo ejercido era de rechazo/negativo (baja afectividad). Los resultados a los que llegaron fueron los siguientes: (a) se presentan problemas de ajuste socioemocional posterior tanto en niños con bajos niveles de emocionalidad positiva como en niños con altos niveles de impulsividad; (b) ese estilo educativo ante un hijo impulsivo actuará como factor de riesgo en posteriores conductas de desajuste social, (c) sin embargo, si el hijo tiene una alta emocionalidad positiva le puede favorecer el ajuste posterior porque actúa como factor de protección ante este estilo educativo parental.

Por último, Rubin, Burgess y Hastings (2002) intentaron reflejar la interacción existente entre altos niveles de inhibición a los dos años y alta frecuencia de conductas de negación a los cuatro años con un estilo educativo materno con alto nivel de control intrusivo y comentarios altamente ofensivos, hallando que los niños sensibles no podían poner en práctica y mejorar sus habilidades sociales porque este estilo educativo socava el desarrollo de la competencia social y la independencia en este tipo de niños.

Por tanto, y a partir de las investigaciones revisadas dentro del modelo interactivo, hemos comprobado que el objetivo común de todas ellas ha sido intentar probar la posible interacción existente entre estilo educativo, temperamento y desarrollo emocional pudiendo concluir que:

1. Niños/niñas con temperamento difícil requieren más tiempo y recursos parentales, así como estilos educativos restrictivos y con autoridad para lograr un ajuste adecuado. 
LOS ESTILOS EDUCATIVOS PARENTALES DESDE LOS MODELOS INTERACTIVO Y DE CONSTRUCCIÓN CONJUNTA

2. En niños/niñas con alto nivel de miedo, su ajuste será adaptado cuando el estilo educativo sea poco severo, incluso algo permisivo, con poco control y mayor afectividad.

3. En niños/niñas con alta emocionalidad positiva, su ajuste socioemocional es independiente del estilo educativo parental ejercido, ya que su emocionalidad actúa como factor de protección.

4. A excepción de los estilos: ausente/negligente y autoritario con maltrato físico y/o psicológico, no existen estilos educativos negativos o inadecuados, sino que todos son apropiados si se adaptan a las variables del hijo analizadas en los diferentes estudios revisados.

No obstante, el modelo interactivo presenta un importante hándicap: existen pocas investigaciones empíricas que profundicen en las correlaciones existentes entre estilo educativo, temperamento y desarrollo o ajuste socio emocional. Por ello resulta imprescindible seguir investigando en esta dirección.

\section{Conclusiones}

Como hemos comprobado, en la década de los '90 aparecieron investigaciones centradas en los estilos educativos sobre las estrategias y mecanismos de socialización que utilizaban las familias, donde se sostenía que el hijo/hija aprende las reglas, pautas y relaciones que se establecen entre sus integrantes, principalmente con su madre y padre. Este aprendizaje determinaba el tipo de interacciones o relaciones interpersonales que mantendría el hijo con sus progenitores, estableciéndose la trayectoria vital en su convivencia.

Por otra parte, a pesar de lo establecido desde el modelo de construcción conjunta, los mismos progenitores pueden establecer un determinado estilo educativo con un hijo y no utilizarlo con otro. Presentar, a su vez, estilos mixtos y cambiantes con un mismo hijo/hija o que un mismo estilo parental provoque conductas adaptativas o desadaptativas en según qué hijo o hija. Por tanto, deben aparecer otros factores que determinen la influencia de un estilo educativo en una dirección u otra sobre el comportamiento de la descendencia estableciéndose correlaciones que van más allá de la simple suma o bidireccionalidad de variables, como lo expuesto por el modelo interactivo. Nos referimos al temperamento, la emocionalidad positiva/negativa o los niveles de miedo del hijo que condicionarán a los progenitores como educadores (mecanismos y estrategias), al vínculo relacional parento-filial que se establezca, y las consecuencias comportamentales de un estilo educativo concreto en determinado hijo/hija.

En función de los resultados obtenidos, cuando en los trabajos revisados en el modelo interactivo se vinculan estilos educativos y temperamento en relación con el ajuste socioemocional del hijo, es complejo fijar conclusiones acerca de la manera en que correlacionan. Sin embargo, sí podemos establecer para determinar pautas educativas dirigidas a padres que cuando se educa a niños cuyo 
temperamento es difícil, su emocionalidad es negativa y existen bajos niveles de miedo, necesitan mayor cantidad de tiempo y de recursos (a veces de apoyo profesional) y estilos con autoridad o restrictivos para que su hijo/hija logre un nivel de ajuste socioemocional óptimo. En contrapartida, los niños y niñas que presenten un alto nivel de miedo y de culpabilidad requieren de estilos educativos menos restrictivos, más laxos e incluso permisivos para que no tengan ansiedad y estrés que, en algunos casos, se traduce en conductas problemáticas o agresivas.

Otra conclusión que puede determinar pautas educativas para los progenitores dentro del modelo interactivo se centra en que los niños/niñas con una emocionalidad positiva (alto nivel de contención, de empatía y de sentimiento de culpa) obtendrán un ajuste socioemocional adecuado independientemente del estilo educativo ejercido por sus progenitores, ya que ese tipo de emocionalidad actúa como factor de protección del sujeto. Quizá aquí radique parte de la explicación de la resiliencia.

La diversidad de perspectivas sobre la relación parento-filial a partir de los estilos educativos, sus consecuencias vinculadas a dimensiones específicas (conductuales, emocionales y de ajuste social) abren nuevas líneas de investigación que deben refutar y/o ratificar concepciones ampliamente aceptadas en algunos ámbitos educativos porque aunque los progenitores tienen gran parte de responsabilidad en el desarrollo adaptativo de los hijos/hijas, no es determinante. Es cierto que los estilos educativos influyen en la socialización y educación de la progenie, pero no necesariamente sus efectos en la conducta de los hijos/as son proporcionales a las causas que determinan algunas conductas antisociales y/o conflictivas en éstos.

En suma, se requieren investigaciones interdisciplinares -conjuntamente desde ámbitos científicos como la Pedagogía y la Psicología, entre otros- y dentro del modelo interactivo que logren replicar tanto el diseño experimental como los resultados revisados con el fin de facilitar la intervención familiar a los profesionales. Sin embargo, somos conscientes de que el estudio en este ámbito es difícil puesto que estamos situados ante una realidad compleja, afectada por gran número de variables e influida por la diversidad de contextos en donde la familia se desarrolla e interactúa. Si bien se han producido avances significativos en el campo metodológico, utilizando muestras más representativas que han contribuido a lograr datos más sólidos, pensamos que es necesario pasar de "mirar a la familia" a "mirar con la familia". Ciertamente esto nos permitirá realizar un análisis de necesidades más ajustado a la realidad familiar, al tiempo que nos llevará a plantear marcos teóricos más flexibles donde el proceso educativo parental esté mejor representado. 
LOS ESTILOS EDUCATIVOS PARENTALES DESDE LOS MODELOS INTERACTIVO Y DE CONSTRUCCIÓN CONJUNTA

\section{REFERENCIAS BIBLIOGRÁFICAS}

Alonso, J. y Román, J. M. ${ }^{a}$ (2005) Prácticas educativas familiares y autoestima. Psicothema, 17 (1), 76-82.

AROCA, C. (2011) La violencia filio-parental: una aproximación a sus claves. Valencia, Universitat de Valéncia.

Ato, E.; Galián, M. ${ }^{a}$ D. y HuÉsCAR, E. (2007) Relaciones entre estilos educativos, temperamento y ajuste social en la infancia: Una revisión. Anales de Psicología, 23 (1), 33-40.

Aunola, K.; Stattin, H. y Nurmi, J. E. (2000) Parenting styles and adolescent's achievement strategies. Journal of Adolescence, 23 (2), 205-222.

Baldwin, A. L.; Kalhom, J. y Breese, F. (1945) Patterns of Parent behavior. Psychology Monographs, 58 (3) (número completo, 268).

BALZANO, S. (2002) Las construcciones culturales sobre el éxito y el fracaso escolar y sus implicaciones sobre los modelos educativos en Argentina. Cultura y Educación, 3 (14), 283-296.

BARBer, B. K. y HARMON, E. L. (2002) Violating the self: parental psychological control of children and adolescents, en BARBER, B. K. (ed.) Intrusive parenting: how psychological control affects children and adolescents. Washington, American Psychological Association, $15-52$.

Bates, J. E.; Pettit, G. S.; Dodge, K. A. y Ridge, B. (1998) Interaction of temperamental resistence to control and restrictive parenting in the development of externalizing behaviour. Developmental Psychology, 34, 982-995.

Baumrind, D. (1971a) Harmonious parents and their preschool children. Development Psychology, 4 (1), 92-102.

- (1971b) Current patterns of parental authority. Developmental Psychology Monographs, 4, 1-102.

BeCKER, W. C. (1964) Consequences of different kinds of parental discipline, en Hoffman, M. L. y Hoffman, L. W. (eds.) Review of Child Development Research, vol. 1. Nueva York, Russell Sage Foundation, 169-208.

Blackson, T. C.; TARTER, R. E. y Mezzich, A. C. (1996) Interaction between childhood temperament and parental discipline practices on behavioral adjustment in preadolescent sons of substance abuse and normal fathers. American Journal of Drug and Alcohol Abuse, 22, 335-348.

Buss, A. H. (1995) Personality: Temperament, Social Behavior and Self. Needhamm Heits, Massachusetts, Allyn \& Bacon.

CARTer, R. J. (1982) Family correlates of male and female delinquency. Criminology, 20, $149-167$.

Cava, M. ${ }^{a}$ J.; Musitu, G. y Murgui, S. (2006) Familia y violencia escolar: el rol mediador de la autoestima y la actitud hacia la autoridad institucional. Psicothema, 18 (3), 367-373.

Ceballos, E. y Rodrigo, M. J. (1998) Las metas y estrategias de socialización entre padres e hijos, en Rodrigo, M. J. y Palacios, J. (eds.) Familia y desarrollo bumano. Madrid, Alianza, 225-243.

CHAO, R. K. (2001) Extending research on the consequences of parenting style for ChineseAmericans and European-Americans. Child Development, 72 (6), 1832-1843.

Colder, C. R.; Lochman, J. E. y Wells, K. C. (1997) The moderating effects of children's fear and activity level on relations between parenting practices and childhood symptomatology. Journal of Abnormal Child Psychology, 25, 251-263. 
LOS ESTILOS EDUCATIVOS PARENTALES DESDE LOS MODELOS INTERACTIVO Y DE CONSTRUCCIÓN CONJUNTA

Collins, W. A. y LAUREN, B. (2004) Parent-adolecent relationships and influences, en LERNER, R. M. y StEInBerg, L. (eds.). Handbook of adolescent psychology. N. Jersey, Willey, 331-361.

Coloma, J. (1993) Estilos educativos paternos, en Quintana, J. M. ${ }^{a}$ (coord.) Pedagogía familiar. Madrid, Narcea, 45-58.

Corvo, K. y Williams, K. (2000) Substance abuse, parenting styles and agression: an exploratory study of weapon carrying students. Education, 46 (1), 1-13.

Craig, G. J. (1996) Desarrollo Psicológico. México, Prentice-Hill Hispanoamericana S. A.

CrockenberG, S. B. (1981) Infant irritability, mother responsiveness, and social support influences on the security infant-mother attachment. Child Development, 52, 857-865.

Darling, N. y Steinberg, L. (1993) Parenting style as a context: An integrative model. Psychological Bulletin, 113, 487-496.

Early, D. M.; Rimm-Kauffman, S. E.; CoX, M. J. y Saluja, G. (1999) Predicting children's wariness in the transition to kindergarten. Póster presentado en Society for Research and Child Development. Alburquerque.

Estévez, E.; Murgui, S.; Moreno, D. y Musitu, G. (2007) Estilos de comunicación familiar, actitud hacia la autoridad institucional y conducta violenta del adolescente en la escuela. Psicothema, 19 (1), 108-113.

FARRINGTON, D. P. y WELSH, B. (2007) Saving children from life crime. Early risk factors and effective interventions. Oxford (UK), Oxford University Press.

Fletcher, A. C.; Steinberg, L. y Williams-Wheeler, M. (2004) Parental Influences on Adolescent Problem Behavior. Revising Stattin and Kerr. Child Development, 75, 781-796.

Galambos, N. L.; Barker, E. T. y Almeida, D. M. (2003) Parents do matter: Trajectories of change in externalizing and internalizing problems in early adolescence. Child Development, 74, 578-594.

Gallagher, K. C. (2002) Does child temperament moderate the effect of parenting on adjustment? Developmental Review, 22, 623-643.

García, M. C. C.; Peregrina, S. y Lendínez, J. (2002) Los estilos educativos de los padres y la competencia psicosocial de los adolescentes. Anales de Psicologia, 33 (1), 79-95.

GARRIDO, V. (2005) Manual de intervención educativa en readaptación social. Vol. 1. Fundamentos de intervención. Valencia, Tirant lo Blanch.

- (2007) Antes que sea tarde. Cómo prevenir la tiranía en los hijos. Barcelona, Nabla Ediciones.

Garrido, V.; Stangeland, P. y Redondo, S. (2006) Principios de Criminología. Valencia, Tirant lo Blanch.

Glueck, S. y Glueck, E. (1956) Physiquen and delinquency. Nueva York, Harper.

GotTman, J. y De Claire, J. (1997) Inteligencia emocional e a arte de educar nossos filos. Rio de Janeiro, Editorial Objetiva (29. ${ }^{\mathrm{a}}$ ed.).

HarRIS, J. R. (2002) El mito de la educación. Barcelona, Grijalbo.

HengGeler, S. W. (1989) Delinquency in adolescents. Newbury Park (USA), Sage.

Herrera, E.; Brito de la Nuez, A. G.; Pérez lópez, J.; Martínez, M. ${ }^{a}$ T. y Díaz, A. (2001) Percepción de estilos educativos parentales e inadaptación en adolescentes. Revista de Psicología Universitas Tarraconenses, 23 (1-2), 44-57.

HiRSCHI, T. (1969) Causes of delinquency. Berkeley, University of California Press.

Hoffman, M. L. (1970) Conscience, personality and socialization techniques. Human Development, 13, 90-126. 
LOS ESTILOS EDUCATIVOS PARENTALES DESDE LOS MODELOS INTERACTIVO Y DE CONSTRUCCIÓN CONJUNTA

Hyde, J. S.; Else-Quest, N. M.; Goldsmith, H. H. y Biesanz, J. C. (2004) Children's temperament and behaviour problems predict their employed mother's work functioning. Child Development, 75 , 580-594.

IzuzQuiza, J. (2003) Filosofía del presente. Una teoría de nuestro tiempo. Madrid, Alianza Editorial.

Jacobson, K. C. y Crockett, I. J. (2000) Parental monitoring and adolescent adjustment: An ecological perspective. Journal of Research on Adolescence, 10, 65-97.

Kaufmann, D.; Gesten, E.; Santa lucía, R. C.; Salcedo, O.; Rendina-Gobioff, G. y Gadd, R. (2000) The relationship between parenting style and children's adjustement: the parent's perspective. Journal of Child and Family Studies, 8 (2), 231-245.

Kim, H. y ChUNG, R. H. G. (2003) Relationship of recalled parenting style the self-perception in Korea American College Students. Journal of Genetic Psychology, 164 (4), 481-492.

Kim, K. y Rohner, R. P. (2002) Parental warmth, control and involvement in schooling. Predicting academic achievement among Korean American adolescents. Journal of Crosscultural Psychology, 33 (2), 127-140.

Kochanska, G. (1993) Towards a synthesis of parental socialization and child temperament in early development of conscience. Child Development, 64, 324-347.

- (1995) Children's temperament, mother's discipline and security of attachment: Multiple pathways to emerging internalization. Child Development, 66, 597-615.

- (1997a) Multiple pathways to conscience for children with different temperaments: From toddlerhood to age 5. Developmental Psychology, 33 (2), 228-240.

- (1997b) Mutually responsive orientation between mothers and their young children: implications for early socialization. Child Development, 68 (1), 94-112.

Laible, D. J. y Carlo, G. (2004) The differential relations of maternal and paternal support and control to adolescent social competent, self-worth, and sympathy. Journal of Adolescent Research, 19, 759-782.

Lamborn, S. D.; Mounts, N. S.; Steinberg, L. y Dornbuschu, S. M. (1991) Patterns of competence and adjustment among adolescents from authoritative, authoritarian, indulgent and neglectful families. Child Development, 62 (5), 1049-1065.

LenguA, L. J. y Kovacs, E. A. (2005) Bidireccional Associations between Temperamental and Parenting, and the Prediction of Adjustment problems in Middle Childhood. Journal of Applied Developmental Psychology, 26, 21-38.

Lengua, L.; WolchiK, S. A.; SAndler, I. N. y West, S. G. (2000) The additive and interactive effects of temperament and parenting in predicting adjustment problems of children of divorce. Journal of Clinical Child Psychology, 29, 232-244.

López, E. (1998) La familia, nuevo contexto educativo ante el conflicto y la esperanza. Revista Complutense de Educación, 9 (2), 79-100.

López, N. L.; Bonenberger, J. L. y Schneider, H. G. (2001) Parental disciplinary history, currents levels of empathy and moral reasoning in young adults. North American Journal of Psychology, 3 (1), 193-204.

LYkKen, D. (2000) Happiness. Nueva York, St. Martin's Griffin.

Maccoby, E. y Martin, J. A. (1983) Socialization in the context of the family: parent-child interaction, en Hetherington, E. M. y Mussen, P. H. (eds.) Handbook of child psychology. Vol. 4. Socialization, personality and social development. Nueva York, Wiley, 1-101.

Mangelsdorf, S.; Gunnar, M.; Kestenbaum, R.; Lang, S. y Andreas, D. (1990) Infant proneness-to-distress temperament, maternal personality, and infant-mother attachment: Associations and goodness of fit. Child Development, 61, 820-831. 
LOS ESTILOS EDUCATIVOS PARENTALES DESDE LOS MODELOS INTERACTIVO Y DE CONSTRUCCIÓN CONJUNTA

Molpereces, M. ${ }^{a}$ A.; Luinares, L. I. y Musitu, G. (2001) Estilos de disciplina familiar y prioridades de valor en la adolescencia. Revista de Psicología social aplicada, 11 (3), 49-67.

Moreno, M. ${ }^{a}$ C. y Cubero, R. (1990) Relaciones sociales: familia, escuela, compañeros. Años preescolares, en Palacios, J.; Marchesi, A. y Coll, C. (eds.) Desarrollo psicológico y educación I. Psicología Evolutiva. Madrid, Alianza Editorial, 219-232.

Musitu, G. y García, J. F. (2001) ESPA29. Escala de Socialización Parental en la Adolescencia. Madrid, TEA ediciones.

- (2004) Consecuencias de la socialización familiar en la cultura española. Psicothema, 16 (2), 288-293.

Nardone, G.; GiannotTi, E. y Rocchi, R. (2003) Modelos de familia. Conocer y resolver los problemas entre padres e hijos. Barcelona, Herder.

NÚÑEZ CUBERO, L. et al. (2006) Emociones y educación: una perspectiva pedagógica, en Asensio, J. M.; García Carrasco, J.; Núñez Cubero, L. y larrosa, J. (coords.) la vida emocional. Las emociones y la formación de la identidad humana. Barcelona, Ariel, 171-195.

Ochaita, E. (1995) Desarrollo de las relaciones padres/hijos. Infancia y Sociedad, 30, 206-227.

Oliva, A.; PARra, A.; Sánchez-Queija, I. y LÓPez, F. (2007) Estilos educativos maternos y paternos: Evaluación y relación con el ajuste del adolescente. Anales de Psicología, vol. 23, n. ${ }^{\circ} 1$ (junio), 49-56.

ORTE, C. y GIFES, F. (2005) Los programas de prevención de drogas centrados en la familia. Una visión desde la investigación práctica. Proyecto Hombre: Revista de la Asociación Proyecto Hombre, 53, 14-17.

- (2006) Volver a ser una familia después de la droga: aplicación de un programa para reforzar la competencia familiar. Proyecto Hombre: Revista de la Asociación Proyecto Hombre, 57, 43-46.

Palacios, J. (1999) La familia y su papel en el desarrollo afectivo y social, en LóPEz, F.; ETXEbarría, I.; Fuentes, M. J. y Ortiz, M. J. (coords.) Desarrollo afectivo y social. Madrid, Pirámide, 267-284.

PARK, S.; Belsky, J.; PUTNAM, S. y CRnic, K. (1997) Infant emotionality, parenting, and 3-year inhibitions: Exploring stability and lawful discontinuity in a male sample. Developmental Psychology, 33, 218-227.

Parke, R. D.; Coltrane, S.; Duffy, S.; Buriel, R.; Dennis, J.; Powers, J.; French, S. y Widaman, K. F. (2004) Economic stress, parenting and child adjustment in Mexican American and European American families. Child Development, 75 (6), 1632-1656.

PARRA, A. y Oliva, A. (2006) Un análisis dimensional sobre las dimensiones relevantes del estilo parental durante la adolescencia. Infancia y Aprendizaje, 29, 453-470.

Parra, A.; Oliva, A. y SÁncheZ-QueIJA, I. (2004) Evolución y determinantes de la autoestima durante los años adolescentes. Anales de Psicología, 35, 331-346.

Patterson, G. R. (1986) Performance models for antisocial boys. American Psychologist, 41, 432-444.

Peralbo, M. y Fernández Amado, M. ${ }^{a}$ L. (2003) Estructura familiar y rendimiento escolar en Educación Secundaria Obligatoria. Revista Galego-Portuguesa de Psicología e Educación, 7 (8), 309-322.

Pérez, P. M. ${ }^{a}$ y CÁnOVAS, P. (1996) Valores y estilos familiares de educación, en Pérez, P. M. ${ }^{a}$; CÁNovas, P.; Alonso, T.; Avellanosa, I. y Vidal, M. Valores y pautas de crianza familiar. El niño de O a 6 años. Estudio interdisciplinar. Madrid, Fundación Santa María, 113-157. 
LOS ESTILOS EDUCATIVOS PARENTALES DESDE LOS MODELOS INTERACTIVO Y DE CONSTRUCCIÓN CONJUNTA

PÉrez de Pablos, S. (2003) El papel de los padres en el éxito escolar de los hijos. Madrid, Santillana.

Pérez Díaz, V.; Rodríguez, C. y SÁnchez, L. (2001) La familia española ante la educación de los hijos. Barcelona, Fundación "La Caixa".

PetTiT, G. S. y LAIRD, R. D. (2002) Psychological control and monitoring in early adolescence: the role of parental involvement and earlier child adjustment, en BARBER, B. K. (ed.). Intrusive parenting: how psychological control effects children and adolescents. Washington, American Psychological Association, 97-123.

PINKER, S. (2004) La tabla rasa. Barcelona, Paidós.

ROMERO, Cl. (2008) ¿Educar las emociones? Paradigmas científicos y propuestas pedagógicas. Cuestiones pedagógicas, 18, 107-122.

Rubin, K.; Burgess, K. y Hastings, P. (2002) Stability and social-behavioral consequences of toddlers", inhibited temperaments and parenting behaviors. Child Development, 73 , 483-495.

RUTTER, M. (1997) Clinical implications of attachment concepts, en ATKINSON, L. y ZUCKER, K. J. (eds.) Attachment and psychopathology. Nueva York, Guilford, 17-46.

RYgaARD, N. P. (2008) El niño abandonado. Barcelona, Gedisa Editorial.

SAnson, A.; Hemphill, S. y Smart, D. (2004) Connections between temperament and social development: a review. Social Development, 13, 142-170.

SCHAEFER, E. S. (1959) A circumplex model for maternal behavior. Journal of Abnormal Social Psychology, 59, 226-235.

SChneider, W.; Cavell, T. y Hugues, J. (2006) A sense of containment: Potential moderator of the relation between parenting practices and children's externalizing behaviours. Development and Psychopathology, 15, 95-117.

Sears, R. R.; Maccoby, E. E. y Levin, H. (1957) Patterns of child rearing. Evanston, Illinois, Row \& Peterson.

Silk, J.; Morris, A.; Kanaya, T. y Steinberg, L. (2003) Psychological Control and Autonomy Granting: Opposite Ends of a Continuum or Distinct Constructs? Journal of Research on Adolescence, 13, 113-128.

Solé, I. (1998) Las prácticas educativas como contextos de desarrollo, en Coll, C. (ed.) Psicología de la educación. Barcelona, Edhasa, 137-216.

Stanger, C.; Dumenci, L.; Kamon, J. y Burstein, M. (2004) Parenting and children's externalizing problems in substance-abussing families. Journal of Clinical Child and Adolescent Psychology, 33 (3), 590-600.

STANHOpe, L. N. (1999) Preschoolers' sharing as related to order, temperament and parenting styles. Póster presentado en Society for Research in Child Development. Alburquerque.

Stattin, H. y KerR, M. (2000) Parental monitoring: A reinterpretation. Child Development, $71,1072-1085$.

Synder, J. y PATterson, G. R. (1987) Family interaction and delinquent behavior, en Quay, H. C. (ed.). Handbook of juvenile delinquency. Nueva York, Wiley.

- (1995) Children's temperament, mother's discipline and security of attachment: Multiple pathways to emerging internalization. Child Development, 66, 597-615.

- (1997a) Multiple pathways to conscience for children with different temperaments: From toddlerhood to age 5. Developmental Psychology, 33 (2), 228-240.

- (1997b) Mutually responsive orientation between mothers and their young children: implications for early socialization. Child Development, 68 (1), 94-112. 
Thompson, M. J.; Raynor, A.; Cornah, D.; Stevenson, J. y Sonuga-Barke, E. J. S. (2002) Parenting behaviour described by mothers in a general population sample. Child Care, Health \& Development, 28 (2), 149-155.

Torío, S.; PeÑa, J. V. e IndA, M. (2008a) Estilos de educación familiar. Psicothema, 20, 62-70.

Torío, S.; Peña, J. V. y Rodríguez M. ${ }^{a}$ C. (2008b) Estilos educativos parentales. Revisión bibliográfica y reformulación teórica. Teoría de la Educación, 20, 151-178.

Torres, M.; Alvira, F.; Blanco, F. y SANDI, M. (1994) Relaciones padres/hijos. Madrid, Ministerio de Asuntos Sociales.

WANG, Q. y LI, J. (2003) Chinese children's self-concepts in the domains of learning and social relations. Psychology in the Schools, 40 (1), 85-101.

Warash, B. G. y Markstrom, C. A. (2001) Parental perceptions of parenting styles in relation to academic self-esteem of preschooles. Education, 121 (3), 485-493.

West, D. J. y Farrington, D. P. (1973) Who Becomes Delinquent? Londres, Heinemann Educational. 